Bond University

Research Repository

\title{
What do consumers want to know about drugs (medication and lifestyle) in their pregnancy journey?
}

Pijpers, Eva L.; McGuire, Treasure M; Kreijkamp-Kaspers, Sanne; Deckx, Laura; Brodribb, Wendy; Van Driel, Marie

Published in:

Research in Social and Administrative Pharmacy

DOI:

10.1016/j.sapharm.2016.05.053

Licence:

Free to read

Link to output in Bond University research repository.

Recommended citation(APA):

Pijpers, E. L., McGuire, T. M., Kreijkamp-Kaspers, S., Deckx, L., Brodribb, W., \& Van Driel, M. (2016). What do consumers want to know about drugs (medication and lifestyle) in their pregnancy journey? Research in Social and Administrative Pharmacy, 12(5), e20. https://doi.org/10.1016/j.sapharm.2016.05.053

\section{General rights}

Copyright and moral rights for the publications made accessible in the public portal are retained by the authors and/or other copyright owners and it is a condition of accessing publications that users recognise and abide by the legal requirements associated with these rights.

For more information, or if you believe that this document breaches copyright, please contact the Bond University research repository coordinator. 


\section{0}

\section{Unconscious implicit attitudes as a predictor of medicines adherence and self-medication}

James A. Green ${ }^{1}$, Mudassir Anwar ${ }^{1}$, Pauline Norris ${ }^{1}$, Oulmann Zerhouni ${ }^{2}$, Aurélie Gauchet ${ }^{2}$. School of Pharmacy, University of Otago ${ }^{1}$, Dunedin, NZ; Laboratoire Interuniversitaire de Psychologie, Université Grenoble Alps ${ }^{2}$, Grenoble, FRANCE.

Introduction. Unintentional non-adherence most often means forgetting, whereas intentional non-adherence involves a conscious choose to stop taking a medicine. However, dual process models of cognition suggest that automatic unconscious processes can underpin conscious, apparently intentional, choices. That is, our prior experiences with medicines can produce attitudes and associations that we are not necessarily consciously aware of, and that these may be key predictors of intentional choice.

Aims. To determine whether implicit attitudes contribute unique prediction to both medicines adherence and to selfmedication.

Methods. Study 1 was a prospective cohort study, with a random sample of 152 people aged 18-65 recruited from the Dunedin telephone directory. Each participant completed a series of questionnaires at Time 1, including an implicit measure of attitudes towards medicines (Green et al, in press). They were then followed up each day for 30 days and asked if they had experienced symptoms, and if so, what actions they took in response. Study 2 was a cross-sectional study, with a convenience sample of 74 participants. Participants completed implicit and explicit measures of attitudes towards medicines as well as measures of adherence.

Results. In Study 1, having a negative attitude towards conventional medicines predicted great use of self-medication, O.R. 0.51, $\mathrm{P}<.05$. In Study 2, positive attitudes towards conventional medicines were associated with higher levels of adherence, $r(74)=.45, \mathrm{P}<.01$.

Discussion. The implicit measure of attitudes to medicines was a strong predictor of both self-medication and medicines adherence, even when controlling for explicit attitude. Therefore, interventions to improve adherence and promote rational self-medication need to consider the role of automatic processes alongside conscious choice.

Green J et al (in press) J Health Psychol

\section{1}

What do consumers want to know about drugs (medication and lifestyle) in their pregnancy journey? Eva L Pijpers $^{3,4}$, Treasure M McGuire $^{1,2,5}$ Sanne Kreijkamp-Kaspers ${ }^{3}$, Laura Deckx ${ }^{3}$, Wendy Brodribb ${ }^{3}$, Mieke L van Driel $^{3}$

School of Pharmacy, The University of Queensland ${ }^{1}$, Brisbane QLD; Mater Pharmacy Services, Mater Health Services ${ }^{2}$, Brisbane, QLD; Discipline of General Practice, School of Medicine, The University of Queensland ${ }^{3}$, Herston, QLD; Faculty of Medicine, Rijksuniversiteit Groningen ${ }^{4}$, Groningen, the Netherlands; Faculty of Health Sciences \& Medicine, Bond University ${ }^{5}$, Gold Coast, QLD.

Introduction. Drug use during pregnancy is common; yet data to support safety are mainly case reports and retrospective studies. There is also growing evidence for harmful fetal effects when treatment of certain maternal conditions is inadequate. Seeking information is a coping strategy and can assist with decision-making.

Aim. This study aimed to identify the medicines information needs of women across pregnancy stages and explore whether their questions could be justified by actual pregnancy risk.

Methods. We conducted a retrospective, mixed method study of pregnancy-related calls to an Australian consumer medicines call centre, NPS Medicines Line (September 2002-June 2010). Call characteristics were compared for pregnancy $(n=4,573)$ and non-pregnancy $(n=118,547)$ questions. Drugs of interest, motivations to call and question themes were analysed across pregnancy stages, with medicines assessed for risk, using the Australian categorisation system for prescribing medicines in pregnancy. Call narratives were explored for stage-specific themes.

Results. Pregnancy-related enquiries were prompted more often by conflicting or inadequate information and request for second opinion. Most questions concerned safety. Psychotropic medication and fertility were strong drivers to seek information in preconception. Everyday illnesses and self-medication with Over-The-Counter products were of increasing concern as pregnancy progressed, with medicines classified as 'safe' accounting for $34 \%$ of questions.

Conclusion. Analysis of real world, pregnancy-related questions demonstrates that women are concerned about safe drug use in pregnancy and are likely to overestimate risk. Health care professionals should proactively address drug information gaps of women's pregnancy stage-specific information needs during routine consultations. 